\title{
Seven Snags of Research Ethics on the Qualitative Research Voyage
}

\author{
MacDonald Kanyangale ${ }^{1}$ \\ ${ }^{1}$ Graduate School of Business \& Leadership, University of KwaZulu-Natal, Durban, South Africa \\ Correspondence: MacDonald Kanyangale, Graduate School of Business \& Leadership, University of \\ KwaZulu-Natal, Durban, South Africa.
}

Received: October 9, 2018

Accepted: October 23, $2018 \quad$ Online Published: May 16, 2019

doi:10.5539/ibr.v12n6p1

URL: https://doi.org/10.5539/ibr.v12n6p1

\begin{abstract}
Responsible researchers with ethically sound research skills are fundamental to success in an ever-changing business and social world. Embedding ethics into research by students seems to be intuitively easy given tight, standardized ethical guidelines and rigorous ethical approval process in the university. In reality, there are Masters and $\mathrm{PhD}$ research students who feel ill-prepared when they encounter ethical ambiguities and complexities in the field which are unique, beyond what they had foreseen at the outset of a qualitative inquiry or were prescribed, advised and forewarned by a research ethics committee (REC).

The aim of this conceptual paper is to discuss seven pitfalls of research ethics in a qualitative research voyage in order to educate and sensitize current and prospective research students. The seven pitfalls are: (1) complexity and ambiguity of informed consent; (2) embedding informed consent as a process rather than an event; (3) navigating the moral conundrum of unintentional disclosure; (4) dealing with deductive disclosure; (5) dialectic between participant`s desire for recognition and greater confidentiality; (6) researcher role conflict and (7) difficulty of embedding researcher reflexivity. The paper concludes that only research students who are ethically literate and actively reflexive in the entire research process are more likely to know whenever they encounter ethical pitfalls, deal with them properly; and ultimately entrench relevant skills to conduct ethically sound research. Highlighted are implications for research educators to develop research competence of current and future researchers.
\end{abstract}

Keywords: research ethics, ethical dilemmas, research integrity, qualitative research, Masters and $\mathrm{PhD}$ research

\section{Introduction}

As novel and sustainable solutions are required to address problems in the world, any effort to develop responsible researchers is less successful if some Masters and $\mathrm{PhD}$ research students fail to master the twin imperatives of being able to conduct ethically sound research, but also ethically evaluate research done by others. Current and prospective research students are turning to the university to develop their praxis of research ethics, among other skills. A decade ago, Miller and Boulton (2007:2199) were overt that the "growing mismatch between increasingly standardized ethics procedures and the complex nature of qualitative social research" would be disabling to novice researchers. As if to prove that this assertion is valid, some students are facing difficulties in embedding ethics in their qualitative research.

The voyage of these students, as any experienced qualitative researcher is typified by many contextual, complex, and "ethically important moments" which are unpredictable, subtle and require timely decisions that have ethical ramifications (Guillemn and Gillam, 2004). To be laconic, there are ethical dilemmas or unforeseeable ambiguities in a qualitative research voyage, which are difficult to encapsulate in full on information sheets or signed consent forms administered at the outset of a research inquiry. Pollock (2012:1-6) is insightful that "formulaic procedural resolutions" are pre-determined, and therefore less responsive to emergent ethical issues (e.g. potential risk of unintentional disclosures). Instead, the practice of "micro-ethics" centred on the judgement and integrity of researchers is pronounced as well suited to entrench the ethical nature of qualitative research process rather than increasing regulation.

Kennedy (2006:143) concurs that "while the ethical guidelines for research seem clear at a glance, a closer look at the intimate nature of qualitative research" reveals that there are many ambiguities. Ellis (2007:22) who is an experienced post graduate research supervisor concur: "I haven't come close to addressing all ethical questions that arise in doing research...these questions swirl around me like sand storm in every research project I do or 
supervise". In short, ethics are an inextricable part of research, elusive, pervasive, but also complex to both students and research supervisors. It is therefore baffling to research supervisors and external examiners when postgraduate students are not able to explicitly and meaningfully report on ethical ambiguities in their qualitative research. This invokes a variety of questions: does the absence of ethical dilemmas in research reports imply that research students are simply under-reporting or oblivious of ethical pitfalls and challenges, hoping they do not matter; or failing to discuss how they dealt with genuine ethical challenges and pitfalls, if at all, they actually did? The lack of concrete answers to these critical questions fuel research educators to fathom potential reasons for poor praxis of research ethics by some Masters and $\mathrm{PhD}$ research students of qualitative research, its broader consequences, and possible corrective efforts. Outside the academy, organizational leaders are concerned with failure to develop research competences of employees. This has a negative impact on the mix of skills in the pipeline of leadership and management of research departments. Overall, it is worrisome to the research community as students become not just users of research, but sometimes researchers themselves expected to execute ethically sound research on various issues. Thus, there is an urgent and compelling need to fathom ethical pitfalls in research faced by students and disseminate this epistemic knowledge to all research students, research educators and any institution that educate and develop researchers.

In this vein, the purpose of this conceptual paper is to discuss seven ethical pitfalls and challenges on the qualitative research voyage, and alert current, prospective research students and novice researchers to possible ways of dealing or avoiding research pitfalls without compromising research ethics. The intention of describing the pitfall is by far not to attack those whose work exhibits them. As a point of departure, this paper discusses key paradigms of ethics as a foundation for understanding research ethics within the broad philosophy of ethics in general. Thereafter, the paper discusses specific pitfalls and challenges of research ethics, which are capable of scuppering any unwary Masters and $\mathrm{PhD}$ research student or novice researcher. Finally, the paper encapsulates key implications for embedding research ethics.

\section{Paradigms of Ethics and Concept of Research Ethics}

It is scholarly sound that any endeavour to understand the concept of research ethics is buttressed by extant schools of thought on ethics. Following a cursory review of literature on ethics, three instructive paradigms, namely consequentialism, deontology and virtue ethics are drawn from the work of Collins (2012:149-157), Crockett (2005) and (De Klerk, 2017) to enrich our understanding of ethics in general and research ethics in particular. The three paradigms of ethics are selected for discussion primarily because they espouse relevant philosophy, which inform ethical practice in research, and has been key in influencing the code of ethics used by researchers.

\subsection{Consequentialism Paradigm}

Profoundly, consequentialism requires us to judge our actions as right according to their consequences or achieving some good state of affairs (De Klerk, 2017:262; Schwandt, 2015:91). In this regard, consequentialism upholds the notion that ethics are exogenous to people or a person. Thus, the anticipated outcomes of action are central in judging action as right (Collins, 2012:149-151). In this way, consequentialism embraces "ends-based" theories of ethics that pronounces the importance of analysing the predicted outcome of action or decision to understand moral worth (Thorpe, 2014:261). For example, egoism theory focuses on outcomes in terms of self-interested desires and interest whilst simultaneously caring about the interest of others. Egoism theory is essentially about judging a decision and action as right if it conforms, furthers and not conflicts with one`s self-interest and well-being. Alternatively, social group relativism is a theory of ethics which judges action as right if it conforms to one`s social group`s norms. The association of oneself with ethical standards of a group and sharing of social group interests is useful in defining what is right. Collins (2012:149-151) also posit that cultural relativism is another ethical theory. In simple terms, this theory stress that action is right if it relates, and conforms to national culture and set of laws. Utilitarianism as advanced by Mill and Bentham is a more complex theory within the consequentialism paradigm. It upholds that what matters is the greatest good for the greatest number (Mondal, 2016). Criticisms of consequentialism include the lack of responsiveness to minority interests. Other critics highlight that the ethical primacy of "outcome" downplays the "means" of ethics (Thorpe, 2014:261). In consequentialism, questionable practices are acceptable as long as the consequences are not negative or hurt anyone substantively.

\subsection{Deontological Paradigm}

Deontological theories of ethics posit that action is right if it is something that everyone should do (Collins, 2012:149). This paradigm comprise "rule-based" theories of ethics which stresses that ethical judgments should be grounded in universal, external rules of what is right to do (De Klerk, 2017:262; Schwandt, 2015:91). The 
analogous maxim of deontology is "do as you would be done by" (Crockett, 2005:193). The deontological paradigm inform researchers to ethically focus on "what ought I to do" and not "what do I want to do" (Thorpe, 2014:262). It is prudent to realize that the idea of rightness and wrongness being in the action (the means) distinguishes deontology from consequentialism, which focuses on consequences (ends) of action or decision. It is notable that consequentialism and deontology paradigms share the view that ethics are exogenous to the person or people. Scholars of ethics assert that these two paradigms have influenced the establishment of codes of ethics of research (Thorpe, 2014:262). The common criticism of the "ends-based" and rule-based paradigms of ethics is that they are not comprehensive and exhaustive enough to universally account and guide action in all research situations.

\subsection{Virtue Ethics Paradigm}

Virtue ethics paradigm cast a very different light from consequentialism and deontology. Notably, virtue ethics provides a lens which advocates that the internal, ingrained, subjective values and traits (e.g. honesty, fairness, respect to others, prudence etc.) within or inherent in an individual drive ethical decision-making (Collins, 2012:149; Thorpe, 2014:262). Arguably, virtues or excellence are manifested in practical judgments, and turned into habits which are used frequently and ultimately become part of one`s moral character. Virtue ethics relates to not only voluntary aspirations, but also living beyond the minimum requirement (Crockett, 2005:202). The challenge is that the plethora of virtues is very extensive. Guided by virtue ethics paradigm, researchers rely on their own internalized or inherent value system to determine the best course of action. Virtue ethicists contend that action is right if it strengthens or cultivates moral character (Collins, 2012:149). It is instructive to note that the analogous maxim is "it's not whether you win or lose its how and why you play that matters" (Crockett, 2005:193). In this way, virtue ethics paradigm dismisses the logic of objective rules and exogenous perspectives of ethical universalism. This paper underscores that ethics is not about prescriptions, norms, and ideals external to society but rather part of the social, cultural, and political milieu. As such, qualitative researchers needs to be "guided by good ethical motives and practice", and that each research encounter is unique (Miller and Boulton, 2007:2204). Research ethics is primarily about applying the fundamental theories of ethics to research process, with consideration of what is good for self as well as others (Coghlan and Brannick, 2001). Kennedy (2006:143) cautions research students that the rigorous approval process by REC simply creates "a structure, like the framing in a house. They do not provide the answers to every ethical dilemma that could emerge in the research process". In other words, ethics review is "a short-hand reminder" to Masters and $\mathrm{PhD}$ research students of more complex and context-specific dilemmas of ethics that are yet to come up, and require their attention (Miller and Boulton, 2007:2199). So, what valuable advice need to be given to prospective Masters and PhD research students and any novice researchers to help them to be critical, comprehensive, and creative, but also ultimately entrench research ethics?

\section{Ethical Pitfalls, Cautions and Potential Solutions}

In what follows, the paper focuses on seven ethical pitfalls faced by some research students and their potential solutions. The researcher identified these ethical pitfalls from a review of literature selected because of being relevant to any of the four domains of research ethics, namely procedural, situational, relational, and exiting ethics as suggested by Tracy (2010). The domains proposed by Tracy (2010) were useful, as they seem to cover most aspects of research ethics. The pitfalls identified from literature reflect some of the recurrent, unique, critical, or complex issues, which may facilitate or jeopardise the practice of ethics in a qualitative research.

\subsection{Complexity and Ambiguity of Informed Consent}

Firstly, there is ethical complexity compounded by an ever-increasing scope and variety of interrelated material details that researchers need to provide participants if they are to make an "adequately", informed and voluntary consent (Ellis, 2007). For example, a researcher needs to provide research participants with relevant details such as the purpose and scope of the study, details of his or her organisational affiliation, data collection techniques and procedures but also why it is interesting/important enough for the participant`s to participate in the study. Clarity on what is involved and sort of questions to be asked (e.g. any sensitive or embarrassing question) are pivotal. In addition, the researcher is also required to inform participants of any foreseeable risks, if any. Clarity on the selection of participants but also on the use of results of the study are key for consent to be informed. Furthermore, the variety of information to participants from the researcher includes method of anonymization of data, time given time to participants to consider their participation and also ask any questions (Sanjari, Bahramnezhad, Fomani, Shoghi \& Cheraghi, 2014; Saunders, Kitzinger \& Kitzinger,2014; Schwandt, 2015).

With this spectrum in mind, the challenge is on how comprehensive a qualitative researcher should be in terms of information that is provided to embrace the diversity of salient content for informed consent to be ethical 
(Schwandt, 2015:91-92). While a researcher cannot fully provide information of what they do not know will occur in future, it is equally impossible for participants to fully consent to what is not yet known, and presented to them.

Arguably, a set of three criterion is necessary to make informed consent valid (Miller and Boulton, 2007). Thus, valid, informed consent should be characterized by (1) provision of full and relevant information to inform decision to participate, (2) voluntary participation and (3) competence of participants to make such a decision. Ambiguity arises when consent that is granted is premised on provision of current information which happens to be incomplete; presupposed by insufficient understanding of the nature and purpose of a research, but also inadequate knowledge of how a particular qualitative research will proceed because of uncertainties .As long as neither the research student nor the participant is uncertain or not able to anticipate at the outset all the emergent aspects or how the qualitative study will unfold, one wonder if participants fully know what they are practically consenting to.

As qualitative research is tolerant to unanticipated changes, many codes of research ethics lack definitive or exhaustive guidance on the scope and variety of details to be given to research participants in order to get their informed consent (Martin \& Marker, 2007). Ellis (2007:23) advises that the ethics radar of novice researchers needs to be aligned to the notion that "even when they do get consent from those in their study, they should be prepared for new complexities along the way". This is a very powerful caution to any unwary research student and novice researcher.

\subsection{Embedding Informed Consent as a Process Rather than an Event}

Consent in qualitative research may take the form of "general consent at the beginning" of the study or as an on-going and relational concept (Ellis, 2007:23). Indeed, some research students depict informed consent as a discrete "one-off" act, which is harmonious with the static, audit and accountability model (Vanclay, Baines \& Taylor, 2013). Arguably, the conception of consent as a "once for all event" trivialize the value of consent especially in a research process which is less predictable and emergent. The critical question is how Masters or $\mathrm{PhD}$ research students ensure that participants have also consented to issues that arose after signing the consent form at the beginning of a study. To put it simply, research students face the ethical challenge of how voluntary informed consent procedures are adequately nuanced and sensitive to ethically important situations which unfold in a qualitative inquiry at different times (Miller \& Boulton, 2007:2206). As a potential solution, Masters and $\mathrm{PhD}$ research students need to be ethically literate and creative to view consent as "re-negotiation and decision-making which involves participants" as the research process unfolds (Ellis, 2007:23). Certain stages at which informed consent is organized and negotiated with gatekeepers and participants are decipherable in a research (Miller \&Boulton, 2007). While students identify some of these, they rarely document clearly the process of invitation (e.g. phone, face-to-face, written communication), the response from the participants, the questions asked and answers given, the negotiation of dates and times of interviews, and so on to reflect the "process" of what really happened. In the parlance of Guillemin and Gillam (2004), this is not just about procedural ethics (formal approvals for a study to commence) but rather process ethics (ethics in the course of practice). This is consonant with informed consent as a process and portrayal of on-going interaction to make sure that informed consent is valid (Miller \& Boulton, 2007). On-going interactions between a researcher and participant is vital to ensure informed consent is validated by continued participation of participants in a study (Reid, Brown, Smith, Cope \& Jamieson, 2018:70-74)

Some external examiners observe that research students pursue a narrow view of informed consent mostly limited to a specific stage at the start of the research relationship (Miller \& Boulton, 2007). As post-data collection consent is also necessary, research students at every level and novice researchers have the moral imperative to initially alert participants that confidentiality might be discussed before, during and even after data collection. In this regard, Kaiser (2009) proposes a standardized post-interview confidentiality and consent form signed by every participant at the end of data collection, primarily to extend conversation beyond the initial consent form. One of the demerits of post-data collection consent is when key participants re-consider that their data already collected and analysed should no longer be part of the study (Thorpe, 2014). This raises ethical dilemma in terms of options such as continuing the study without data that is withdrawn or discontinuing the study. In particular, Kaiser (2009:1637) cautions researchers of potential obstacles such as the "lack of standardized process for obtaining additional consent". Without proper guidance, additional consent is unlikely to be obtained to ensure informed consent that is valid throughout the entire research process. It is advisable that research students go beyond the simplistic notion of an overly prescriptive informed consent at a particular stage that expire when data collection ends. The conception of informed consent as a process beyond data collection has a variety of implications. These may include cost of re-contacting participants but also perception of 
unnecessary harassment or further intrusion. Research supervisors need to prepare research students to practice informed consent as a "process" which demands creativity. Informed consent is not a one off event scheduled before commencing the research voyage.

\subsection{Navigating the Moral Conundrum of Unintentional Disclosure}

Fundamental to the relationship between a researcher and participant in a research context is the promise of confidentiality, anonymity and trust (Robertson, 2014). Often, unintended disclosure occur where there is trust and rapport built by a research student with participants in pursuit of participant`s freedom of expression, anonymity, openness and truth. In such relationship, research participants face the potential risk of unintentional disclosure or revelation of details about their organization, others but also themselves (e.g. commercial secrets, people`s private information, evidence of illegal activities or potentially embarrassing details) which may create discomfort or reputational damage if known by others (e.g. public or authorities). To be succinct, this represents a dialectical opposition for a researcher between "expression and protection" (Ellis, 2007:21). The ethical pitfall is that some Masters and $\mathrm{PhD}$ research students are rarely explicit not only when they encounter such dialectical opposition, but also how they deal with it.

Unintentional disclosure with potential to damage an individual participant or participating organisation presents ethical dilemmas for a researcher at three levels. Firstly, there is the level of a participating organization; especially that access is often premised on assured confidentiality, anonymity, and absence of harm (e.g. confidentiality agreements with company). Unintentional disclosure with potentially damaging information creates problems not only when one is studying another organization but also his or her own organization, management or colleagues (Reid et al., 2018:72-74). Secondly, unintentional disclosures also present ethical dilemmas at the individual participant level where signed informed consent, promise of anonymity and confidentiality plus rapport by the researcher gives participants a sense of protection such that they open up and speak freely with a researcher as a confidant (Ellis, 2007:23). Thirdly, the researcher faces the dilemma of whether to express unintentional disclosures as reality or protect an organisation and research participants. For example, a research student may face a variety of potential risks (e.g. witch-hunting and sour work relations with colleagues as participants) if damaging, unintentional disclosures about colleagues are reported as findings of a research even if they are anonymized.

This moral conundrum invokes the question of whether Masters and $\mathrm{PhD}$ research students simply use unintentional disclosure just like any data revealed to them voluntarily by participants or not. Another interesting question is whether these research students pursue expression or protection in reporting potentially damaging unintentional disclosures in a study. At the backdrop of all this is an ethical obligation of research students towards research participants such that some of them report the use of member check to seek consent on what aspects of unintentional disclosures may be used or not without compromising the findings. However, member check or respondent validation is often used by research students as an epistemological tool to ensure research quality (e.g. used to solicit feedback on researcher`s findings, unearth nature of disagreement and their reasons such as error of interpretation, fear of financial or reputational damage if findings are publicized) and seek further clarity (Schwandt, 2015:195-196). While member check is also a potentially strong ethical tool to uphold the truth, some Masters and $\mathrm{PhD}$ research students are not clear on how they use it to deal with instances when a participating organization disagree with all or some findings not because they are not true, but other reasons. Research educators need to train students on how member check is also an ethical act to uphold nothing but the reality or truth in the face of irreconcilable disagreements between a researcher and participants or a participating organization. It is vital that the way Masters and $\mathrm{PhD}$ research students deal with unintentional disclosure should enhance rather than compromise accurate portrayal of reality.

In extreme circumstances where unintentional disclosure reveal evidence of illegal activity, novice researchers are advised that they have an obligation to breach participant confidentiality and anonymity. This has connotations of betrayal of participants by a researcher who initially made assurances of full and not partial confidentiality (Pollock, 2012:2-5). On the other hand, it would also be unethical not to disclose illegality. In instances of moral conundrum, a researcher has to rely on his philosophical understanding of ethics to make best judgement possible, informed by knowledge of a particular context and debates relating to each case (Pollock, 2012).

\subsection{Disguise or Destroy: Dealing with Deductive Disclosure}

Deductive disclosure is also another ethical challenge that research students grapple with on their research voyage. This occurs when traits (e.g. age, gender, number of years of experience etc.) of individuals or groups are identifiable in a research by self or others even if real names are not used (Ellis, 2007; Saunders et al., 2014). 
Christians (2007) highlighted that watertight confidentiality has proved to be impossible in some instances while the reader sometimes recognize pseudonym and disguised locations.

In this regard, anonymity works as far as local people have no objection and cannot be bothered by what is written or there is little scrutiny from outsiders(Walford,2005:86). Inevitably, some scholars deride that anonymity is more of a strategy to gain access as "pseudonyms act to protect people and organization when there is little to protect them from" (Walford, 2005:88).

Anonymity in practice cannot be totally "blanket" (e.g. use of pseudonyms or replacing identifiers to disguise every identifying detail) (Schwandt, 2015; Walford, 2005). As there are multiple clues to a person`s identity (e.g. process of elimination may be used to identify others etc.), it is always not easy for a researcher to predict which data will lead to identification and require anonymization. While greater level of anonymization seems desirable to avoid deductive disclosure, it also poses the risk of making data less useful because of de-contextualization and "decoupling of events from history and geographically specific location (Nespor, 2000:549). Some research students encounter the ethical ambiguity of how much disguising of details in data actually enhances confidentiality or destroys the meaning of data. In this regard, Masters and $\mathrm{PhD}$ research students and novice researchers need to be mindful that anonymity is essentially a "balancing act of compromising some integrity of data to make the most of anonymity and at other times risk anonymity to enhance integrity of data" (Saunders et al., 2014:12). This epitomizes the ethical conflict between conveying rich, accurate, and contextualized details of reality on one hand, and de-contextualization to avoid deductive disclosure on the other. Kaiser (2009:1635) lament that literature and some codes of ethics do not offer specific and practical guidance to novice researchers on how to deal with this ethical tension. This matter deserves urgent attention of research educators if they are to develop students with capacity to conduct ethically sound research.

\subsection{Dialectic Between Participant's Desire for Recognition and Greater Confidentiality}

The researcher-centred approach to select aspects of a person`s story to modify in order to make the research participant unrecognizable to others when the report is published has ethical challenges (Wiles Crow, Heath \& Charles, 2008:422). Disguising of research participant's voice and identifying details to comply with confidentiality is sound; but it may also conflict with participant`s desire for greater recognition in their story especially when it is a positive one (Wiles et al., 2008:422). Concisely, there are dialectical opposites of "participant's desire or right for greater recognition" on one hand, and "anonymity by default" on the other (Wiles et al., 2008:422). How this is dealt with is critical. More importantly, any research student need to be ethically sensitivity to ensure that his or her role in "disguising" data does not impede participant s desire for recognition.

Renegotiation of participants' desire for anonymity or full recognition needs to be open throughout the research voyage, even if there is anonymity agreed at the start of the study (Parry \& Mauthner, 2004). This echoes the value of informed consent as an ongoing process of negotiation of the terms of agreement as the study progresses to ensure that the participant's greater desire for recognition is not compromised. This means re-contacting participants and getting additional or re-envisioned, informed consent based on details and a wider range of confidentiality options e.g. recognition of participants (Kaiser, 2009:1637). In the foreground of considering full recognition of participants, it is imperative that the researcher clearly advises the participant of how their full recognition as research participants relates to the ethical obligation of a researcher to avoid or minimize harm to participants because of participation in a study.

\subsection{Researcher Role Conflict}

A research student may have a variety of formal and informal roles in a research context, which may have impact on a variety of issues on research ethics (Reid et al., 2018:69-75). For example, some MBA research students may specifically introduce themselves as researchers of their own organizations. In such relationship, participant may see the research students in two ways, as a manager and a researcher. Commonly, participants have problems to detach the manager from the research students. Thus, a hierarchical relationship prevails which predates the research and is durable beyond the research period (Sultana, 2007).

These multiple identities, power, and relational dynamics in a study affect the freedom of participants to be more open in the interviews (e.g. sensitive on what to divulge or censure). The researcher may see the need for intervention or provision of managerial advice when work-related problems are raised during interviews with a junior employee (Reid et al., 2018:69-74). Except in action research where there are specific participatory guidelines to avoid this, the paradox is that every intervention reinforces the power dynamics, role of manager, rather than that of a researcher (Reid et al., 2018:71-74). Alternatively, there is a risk that every failure to intervene may potentially decrease the participant`s perception of the manager as a responsible and powerful 
advocate on their behalf. This posits an ethical conundrum to some research students in terms of how to deal with role conflict in a research. The ethical pitfall is manifested when a research student fail to report and reflect on when any of his or her role in a research context affected the qualitative research voyage (Strauss \& Corbin, 1990:186-188).

Furthermore, some research students have friends in their respective organizations who may sometimes be part of research participants (Taylor, 2011:3-12). In this regard, a less hierarchical and multi-faceted relationship prevails. The role of a researcher who is also a friend may shape the researcher`s work, degree of bias, and his or her positioning in the field (Ellis, 2007:4). For example, the researcher may face the difficulty of distinguishing data gathered in conversations with the same person as a friend from what is collected in a designated research-participant context (Ellis, 2007). Furthermore, research participants who are friends of a research student may have expectations of a "friendly", "insider", and more sympathetic researcher (e.g., who has contextual knowledge that pre-dates the research) (Taylor, 2011:3-12). Profoundly, "the problem is not about being friends with participants, but rather acting as a friend and not yet living to the obligation of friendship" (Ellis,2007:13). While sociology, anthropology, and medicine have grappled with the ethical quandary of insider friendships and intimacy between participant and researcher, there is little discussion and guidelines on how to deal with these expectations particularly within management research to inform research students and novice researchers. If the researcher is an insider, it is very possible that the narrative of the student as a researcher and the researched may be entwined (Taylor, 2011:9). This raises ethical pressure or potential for bias, misrepresentation and misinterpretation by a researcher to portray not only the self but also his or her own organization in favourable light (Sanjari et al., 2014). As some Masters and $\mathrm{PhD}$ research students also conduct research in contexts other than their workplaces, they also assume other roles such a (a) stranger, (b) visitor, and (c) initiator (Sanjari et al.,2014; Reid et al., 2018). Overall, the role that a research student adopt in a research context intersect with research relationships and consequently affect the research process in ways that need clarity in the dissertation. As a potential way of addressing researcher role conflict, research students need to engage in a process of self-regulation and active reflection regarding each of the roles that they may have in a research context and explicitly report on how these affected them and others in the research process (Strauss \& Corbin, 1990:186-188).

\subsection{Difficulty of Embedding Researcher Reflexivity}

Phelan and Kinsella (2013:88) are explicit that "discussing reflexivity in relation to ethics and research is easy.... enacting reflexivity in our everyday research practice is far more challenging". Sultana (2007:376) asserts that reflexivity in research is about active "reflection on self, process, and representation, and critically examining power relations and politics in the research process, researcher accountability in data collection and interpretation". On the other hand, reflection is different as it means 'thinking about', and sometimes connotes introspection of an isolated mind in an attempt to address researcher prejudice (Finlay, 2002). While reflection is less interactive, reflexivity at the other end is a more active, intersubjective process, which has learning aspects. This paper upholds the view of reflexivity suggested by Robson (2002: 22). Thus, reflexivity is... an awareness of the ways in which the researcher as an individual with a particular social identity and background has an impact on the research process. It is also noteworthy that reflexivity is characterized as a "methodical process of on-going questioning of the doing of research and also learning about self as a researcher, research participants, others, and the research context which illuminates meanings about personal, theoretical, ethical, and epistemological aspects of the research process" (Kanyangale \& Pearse ,2012). According to Tracy(2010:837-851), ethics is not only about procedural ethics, but also situational ethics(which require reflexivity to deal with unanticipated ethical questions due to the specific nature of the research context ), ethical relationships (e.g. managing multiple identities of the researcher and dynamic researcher-participant relationships) and ethical ethics of anonymity and confidentiality in disseminating findings.

In research reports, it is advisable that Masters and $\mathrm{PhD}$ research students are explicitly reflexive on their own values, professional background, positionality, or subjectivity (Reid et al., 2018). In many instances, there is limited evidence in research reports of some research students that adequately reflect on (1) what they have learnt about themselves as individuals and professionals, (2) what they have learnt about the content, (3) but also what they have learnt about the research process itself (Robson, 2002). In short, there is lack of evidence manifesting sensitivity to the ways in which the researcher (e.g. role of his or her prior assumptions, biases) and the research process have shaped the collected data (Ellis, 2007; Sultana, 2007). It is important that researcher plainly indicate their prior assumptions at the outset of any research report to enhance credibility (Strauss \& Corbin, 1990:186-188).

In general, the recognition that literature lacks prescription on specific types of ethical responses to research 
situations that emerge in the complex and social context of qualitative research compounds the struggle to embed reflexivity in research (Phelan \& Kinsella, 2013:88). Subsequently, Masters and PhD research students are cautioned to reflect-in-action and also reflect-on-action as ethical guidelines fail to offer any explicit guide on how to be reflexive in order to embed situational ethics (Guillemin \& Gillam,2004; Kanyangale \& Pearse,2012). The prescriptive, analytical, and regulatory procedures of ethics cannot help a researcher to anticipate and reinforce exhaustively researcher reflexivity (Guillemin \& Gillam, 2004; Tracy, 2010). As such, researchers need to combine ideals of research ethics with reflexivity (Reid et al., 2018). This is a valuable contribution to the scholarship of how research students endeavour to practice ethics that permeates research, and ultimately demystify the difficulty of ethical research practice by students. After all this, one may ask: what are the implications of these ethical pitfalls and challenges on the development of research skills by research educators?

\section{Implications for Research Praxis and Education}

There are three notable research implications for research educators, Masters and PhD research students, and novice researchers. Firstly, the paper has highlighted that effort to embed ethics in research by students should go beyond rigorous procedures and regulation, exemplified by the gate-keeping exercise by REC. Theories on ethics and researcher reflexivity are vital. Thorpe (2014:262) agrees that "rigid adherence to any ethical code, whether deontological or consequentialist, would seriously restrict the scope for action" when an ethically important moment arises in a research process. In this respect, it is prudent that research educators re-visit the content that is taught in the module of research methods to research students to include paradigms of ethics in general (e.g. consequentialism, deontology, and virtue ethics). This is vital to ensure deep understanding of philosophical thinking behind research ethics in a qualitative research so that any Masters and $\mathrm{PhD}$ research student and novice researcher can meaningfully practice ethics in any unforeseen, complex, and social aspects of qualitative research process. Without robust philosophy on research ethics, two issues are evident. First, the technicalities of doing research ethics or getting ethical clearance approval will remain inadequate to prepare Masters and $\mathrm{PhD}$ research students to deal with novel aspects of research ethics. Second, these research students may have problems to notice when they have actually fallen into ethical pitfalls during a research process, and subsequently how to deal with them. Passive learning, but also inadequate experiential learning evident in traditional teaching methods such as lecturing are not very helpful for post-graduate research students to acquire practical skills to deal with some of the ethical pitfalls when encountered in a qualitative study. While the cognitive understanding of the philosophy of ethics and research ethics by students through classroom interactions between research teacher and student is pivotal, there is also need for carefully designed variety of interactive, hands-on and active learning experiences in which students engage with real research participants as part of research methodology as a practice. There is need for students to develop in all the four domains of ethics as highlighted by Tracy (2010), namely, procedural ethics, process ethics, situational ethics, and ethical relationships in research.

Secondly, it is imperative for researchers to undertake empirical studies of student s challenges in embedding research ethics in qualitative research. These studies may privilege the viewpoint of new graduates or those who examine the research outputs of postgraduate students to offer potential solutions to ethical pitfalls.

Lastly, the praxis of research ethics in a qualitative research needs an interplay of the trinity involving: (1) robust ethical review and regulatory process by REC, (2) researcher`s firm grasp of theories of ethics and research ethics, and (3) ethical researcher reflexivity. An over- emphasis on one aspects of this trinity at the expense of the others may jeopardise overall research ethics. As this trinity is proposed as core to the praxis of research ethics, there is need for research educators and practitioners to delve into how the interplay of theory, REC review and approval of research ethics applications, and researcher reflexivity comes together to make research ethics a reality in a study. Research educators have absolutely no option but centralize better understanding of the philosophy or theories on ethics as a primary foundation if more Masters and $\mathrm{PhD}$ research students are to demonstrate mastery in the praxis of research ethics in qualitative research.

\section{References}

Christians, G. (2007). Cultural Continuity as Ethical Imperative. Qualitative Inquiry, 13(3), 437-444. https://doi.org/10.1177/1077800406297664

Coghlan, D., \& Brannick, T. (2001). Doing Action research in your own organization. London, England: Sage Publication.

Collins, D. (2012). Business Ethics: How to Design and Manage Ethical Organisations. New Jersey, NJ: John Wiley and Sons, Inc. 
Crockett, C. (2005).The Cultural paradigm of Virtue. Journal of Business Ethics, 62,191-208. https://doi.org/10.1007/s10551-005-0190-8

De Klerk, J. J. (2017). The Devil Made Me Do It: An inquiry Into the Unconscious "Devils Within" of Rationalized Corruption. Journal of Management Inquiry, 26(3), 257-269. https://doi.org/10.1177/1056492617692101

Ellis, C. (2007). Telling Secrets, "Revealing Lives: Relational ethics in Research with Intimate Others". Qualitative Inquiry, 13(1), 3-29. https://doi.org/10.1177/1077800406294947

Finlay, L. (2002). "Outing" the researcher: the provenance, process, and practice of reflexivity. Qualitative Health Research, 12 (4), 531-545. https://doi.org/10.1177/104973202129120052

Guillemin, M., \& Gillam, L. (2004). Ethics, reflexivity, and ethically important moments in research. Qualitative Inquiry, 10 (2), 261-280. https://doi.org/10.1177/1056492617692101

Kaiser, K. (2009). Protecting Respondent Confidentiality in Qualitative Research. Qualitative Health Research, 19 (1), 1632-1641. https://doi.org/10.1177/1049732309350879

Kanyangale, M., \& Pearse, N. (2012). Weaving the Threads of Reflexivity: Coming to terms With Grounded Theory. Proceedings of $11^{\text {th }}$ European Conference on Research Methods in Business and Management Studies, University of Bolton, UK, 28-29 June, 2012:190-198.

Kennedy, J. (2006). Grey matters: Ambiguities and Complexities of ethics in research. Journal of Academics Ethics, 3, 143-158. https://doi.org/10.1007/s10805-006-9011-7

Martin, J., \& Marker, D. (2007). Informed consent: Interpretation and practice on social surveys. Social Science \& Medicine, 65, 2260-2271. https://doi.org/10.1016/j.socscimed.2007.08.004

Miller, T., \& Boulton, M. (2007). Changing constructions of informed consent: Qualitative research and complex social worlds. Social Science and Medicine, 65, 2199-2211. https://doi.org/10.1016/j.socscimed.2007.08.009

Mondal, A. L. (2016). Mill's Critique of Bentham's Utilitarianism. International Journal of Philosophy Study, 4, 13-21. https://doi.org/10.14355/ijps.2016.04.003

Nespor, J. (2000). Anonymity and place. Qualitative Inquiry, 6(4), 564-569. https://doi.org/10.1177/107780040000600408

Parry, O., \& Mauthner, N. (2004). Whose data are they anyway? Practical, legal and ethical issues in archiving qualitative research data. Sociology, 38, 139-152. https://doi.org/10.1177/0038038504039366

Phelan, S., \& Kinsella, E. (2013). Picture This...Safety, Dignity, and Voice-Ethical Research with Children: Practical Consideration for the Reflexive Researcher. Qualitative Inquiry, 19(2), 81-90. https://doi.org/10.1177/1077800412462987

Pollock, K. (2012). Procedure versus process: ethical paradigms and the conduct of qualitative research. British Medical Ethics, 13(35), 2-12. https://doi.org/10.1186/1472-6939-13-25

Reid, A. M., Brown, J. M., Smith, J. M., \& Jamieson, S. (2018). Ethical dilemmas and reflexivity in qualitative research. Perspectives on Medical Education, 7, 69-75. https://doi.org/10.1007/s40037-018-0412-2

Robertson, M. (2014) The Case for Ethics Review in Social Sciences: Drawing from Practice at Queen Mary University of London. Research Ethics, 10 (2), 69-76. https://doi.org/10.1177/1747016113511177

Robson, C. (2002). Real World Research (2 $2^{\text {nd }}$ ed.). Oxford, London: Blackwell Publishers.

Sanjari, M., Bahramnezhad, F., Fomani, F., Shoghi, M., \& Cheraghi, M. (2014). Ethical challenges of researchers in qualitative studies: the necessity to develop a specific guideline. Journal of Medical Ethics and History of Medicine, 7(14), 1-6. https://doi.org/10.5539/gjhs.v6n5p301

Saunders, B., Kitzinger, J., \& Kitzinger, C. (2014). Anonymising interview data: challenges and compromise in practices. Qualitative Research, 1-17. https://www.ncbi.nlm.nih.gov/pmc/articles/PMC4582834/

Schwandt, T. A. (2015). The Sage dictionary of qualitative inquiry ( $4^{\text {th }} \mathrm{ed}$.). London: Sage Publications.

Strauss, A., \& Corbin, J. (1990). Basics of Qualitative Research: Grounded theory procedures and techniques. Newbury Park: Sage Publications.

Sultana, F. (2007). Reflexivity, Positionality and Participatory Ethics: Negotiating Fieldwork Dilemmas in International Research. An International E-Journal for Critical Geographies, 6(3), 374-385. 
https://www.acme-journal.org/index.php/acme/article/view/786

Taylor, J. (2011). The intimate insider: negotiating the ethics of friendship when doing insider research. Qualitative research, 11, 3-22. https://doi.org/10.1177/1468794110384447

Thorpe, A. (2014). Doing the right Thing or Doing the Thing Right: Implications of Participant withdrawal. Organizational Research Methods, 17(3), 255-277. https://doi.org/10.1177/1094428114524828

Tracy, S. J. (2010). Qualitative Quality: Eight "big tent" criteria for excellent qualitative research. Qualitative Inquiry, 16, 837-851. https://doi.org/10.1177/1077800410383121

Vanclay, V., Baines, J., \& Taylor, N. (2013). Principles of ethical research involving humans: ethical professional practice in impact assessment part 1. Impact Assessment and Project Appraisal, 3(3), 243-253. https://doi.org/10.1080/14615517.2013.850307

Walford, G. (2005). Research ethical guidelines and anonymity. International Journal of Research \& Methods in Education, 28(1), 83-93. https://doi.org/10.1080/01406720500036786

Wiles, R., Crow, G., Heath, S., \& Charles, V. (2008). The management of confidentiality and anonymity in social science. International Journal of Social Research Methodology, 11(5), 417-428.

https://doi.org/10.1080/13645570701622231

\section{Copyrights}

Copyright for this article is retained by the author(s), with first publication rights granted to the journal.

This is an open-access article distributed under the terms and conditions of the Creative Commons Attribution license (http://creativecommons.org/licenses/by/4.0/). 